\title{
Instrucciones para envenenar a un compositor. La escritura en Amadeus, de Peter Shaffer
}

\section{Lucas Gagliardi \\ Universidad Nacional de La Plata, Argentina \\ lucas.lenguayliteratura@hotmail.com.ar}

Fecha de recepción: 28/02/2018. Fecha de aceptación: 03/04/2018.

\section{Resumen}

En Amadeus (1979) de Peter Shaffer se aborda el supuesto conflicto entre los compositores Mozart y Salieri. La pieza teatral fue reescrita en numerosas ocasiones (incluyendo un guión para cine); las reversiones escriturales de la obra muestran la construcción persistente de un imaginario en torno a la escritura, la cual es percibida como peligro y regula la conflictiva relación entre los personajes. Desde el marco teórico y metodológico de la crítica genética, abordamos la escritura en Amadeus en el texto dramático y cinematográfico firmado por Shaffer.

\section{How to poison a composer. Writing within Amadeus by Peter Shaffer}

\begin{abstract}
Amadeus (1979, Peter Shaffer) explores the supposed conflict between composers Mozart and Salieri. This play was re-written in several occasions (including its adaptation as the screenplay for a famous film). Those different versions show the persistent construction of an imaginary around writing, a practice which is perceived as dangerous and which, at the same time, regulates the conflictive relation between the characters. From the theoretical and methodological frame of genetic criticism, we approach writing and its representations within Amadeus, taking as objects both the dramatic text and the screenplay.
\end{abstract}

Palabras clave

Texto dramático; crítica genética; Shaffer; escritura; Amadeus

Keywords Dramatic Text; Genetic Criticism; Shaffer; Writing; Amadeus 
Did it show? Is talent that written on the face?

\section{Salieri en Amadeus}

La escritura como una forma de conservación, de objetivación de ideas, como tecnología que en otros momentos históricos estaba en manos de una minoría: todas estas ideas las encontramos en estudios sobre la historia de la cultura escrita (Calvet, 2007). No obstante, si nos remitimos a Fedro -y a la lectura que Derrida hace sobre este diálogo (1975)- podemos sumar otra dimensión a nuestras representaciones sobre lo escrito: en aquel diálogo filosófico de Platón, la escritura es descripta como un pharmakon, es decir, tanto un bálsamo como un veneno para la memoria. La escritura se separa de su contexto de origen y de la autoridad interpretativa del escribiente. En este hecho, el filósofo advirtió el peligro de la desposesión que sufre el autor, reflexión que nos reenvía al concepto de firma derrideano, a su vez.

La metáfora del pharmakon y la amenaza que la escritura representa (desposición, perdurabilidad, distorsión) nos sirven como forma de entrada para analizar el imaginario que Peter Shaffer despliega en torno a la escritura en su Amadeus, obra estrenada en 1979 y reescrita en varias ocasiones. Como observaremos, la escritura se transforma en un motivo dentro de la génesis escritural de la obra; es uno de los venenos con los cuales Salieri intoxica no tanto la memoria de Mozart como sí toda su vida hasta llevarlo a la ruina.

\section{Marco teórico y metodológico}

Para esta indagación, nos posicionamos desde la crítica genética (Lois, 2001, 2005; Goldchluk, 2010). La particularidad de los materiales de este estudio (texto teatral, guión cinematográfico) ha sido abordada ya por trabajos geneticistas (Cismondi, 2011; Gagliardi, 2014, 2015; Grésillon, 1995, 1996): se lo concibe como texto en proceso que se encuentra en permanente devenir en hecho teatral o convivio (Dubatti, 2008); en el caso del guión para cine, el carácter transitorio de esa escritura también es lo que la define, aunque a diferencia de los montajes teatrales, el guión desemboque rara vez en más de una realización cinematográfica.

Nuestro trabajo se centrará en un estudio de la escritura shafferiana en torno a la obra Amadeus. Desde el geneticismo, los límites de lo que consideramos obra han sido puestos en jaque gracias a la reconsideración de la misma como un acontecimiento no reductible al texto édito, siendo este en todo caso un conjunto de instancias de archivación en el cual el investigador realiza un corte. En nuestro caso, escogimos analizar los guiones teatrales y cinematográficos de Shaffer guiados por el criterio de la firma autoral (Derrida, 1971; Gagliardi, 2016; Goldchluk, 2010); por este motivo, dejamos de lado para este trabajo el análisis de puestas en escena o de la película de Milos Forman dado que si bien pueden aportar interesantes ideas, implicarían correrse del proceso de escritura de Shaffer para indagar en otros sistemas de signos y configuraciones que requerirían, además, otros materiales para la confección de un dossier genético.

En cuanto a la confección del dossier (Lois, 2001), detallamos a continuación los materiales que relevamos en la fase heurística. En todos los casos se trata de pre-textos redaccionales éditos (Lois, 2001: 20) dado que Shaffer ha conseguido que se publiquen las diferentes revisiones que ha hecho sobre el texto teatral. Basaremos este trabajo en dichos materiales y las utilizaremos nomenclaturas para referirnos a los mismos con mayor agilidad: ${ }^{1}$

1. Para una descripción pormenorizada de los materiales de génesis y del trabajo heurístico remito a Gagliardi (2016). 


\author{
Versión 1: Shaffer, Peter. Amadeus. Londres: André Deutsch, 1980 (recoge la puesta \\ de la temporada de 1979 en Londres);
}

Versión 2: Shaffer, Peter. Amadeus. Londres: Harper Perennial, 1984 (recoge la puesta de la temporada de 1980 en Nueva York);

Versión 3: Shaffer, Peter. Amadeus: the screenplay. Revisión de diciembre, 1982 (guión para la película de Milos Forman;

Versión 4: Shaffer, Peter. Amadeus. Londres: Harper Perennial, 2001 (recoge la puesta de la temporada de 1999 en Nueva York).

La perspectiva genética nos permite indagar tanto en los cambios como en las constantes dentro del proceso creativo; los mismos son interpretados como síntomas de conflictos discursivos. El geneticismo insiste en prestar atención al proceso de escritura en todas sus instancias, intentando no entronizar un estadio textual como el más puro, legítimo o valioso. Se intenta evitar una aproximación teleológica a la escritura (Lois, 2001: 17; 2005: 86-87). Esto es consecuencia de que el interés de la mirada geneticista no sea el de editar el texto más cercano posible al arquetipo textual-objetivo de la ecdótica, por ejemplo- sino interpretar lo que ha ocurrido en el transcurso de la escritura: qué ha puesto en juego el autor, cuáles fueron sus planes, sus cambios, sus recurrencias. Esta mirada vuelve posible, entonces, analizar la poética autoral desde las propias intervenciones realizadas por el sujeto escribiente y los sentidos que de las mismas se desprenden.

Pasaremos a analizar Amadeus y su imaginario en torno a la escritura

\title{
Esos condenados manuscritos
}

Para indagar en el imaginario en torno a la escritura que se despliega en la obra nos conviene recordar que el Mozart histórico se encuentra atravesado por una concepción romántica. El Romanticismo rescató la figura del músico austríaco y la relacionó como encarnación del genio visionario romántico. Se tejió así una leyenda en la que se mezclan su carácter de libertino, de personaje rebelde frente a las convenciones de su época y el supuesto envenenamiento perpetrado por un envidioso Salieri. Sobre la base de esta narrativa, Alexandr Pushkin compuso su Mozart y Salieri (1830), intertexto que analizaremos más adelante. Shaffer se vale de este imaginario para caracterizar a su personaje y la oposición del mismo con Salieri

Si bien algunos musicólogos confirmaron que muchos de los manuscritos mozartianos que han llegado hasta nuestra época poseen un número de correcciones muy bajo, la imagen del escrito genial e impoluto persistió. Sobre la base de esta leyenda, Shaffer traza un imaginario escritural. Comencemos a deshilvanar esta madeja por medio de un ejemplo. En el marco de esta concepción, el músico como encarnación del genio visionario que recibe la inspiración divina resultaba lógico sostener que los manuscritos de Mozart no poseían tachadura o enmienda alguna, es decir, una escritura directa, inspirada y carente de conflictos. En ese hecho, Salieri se apoya para concluir que Mozart es, en efecto, un enviado de la divinidad para señalar su mediocridad y destruirlo. Si bien algunos musicólogos confirmaron que muchos de los manuscritos mozartianos reales que han llegado hasta nuestra época poseen un número de correcciones muy bajo, la imagen del escrito genial e impoluto ha persistido. Comencemos a deshilvanar esta madeja por medio de un ejemplo.

Hacia el final del primer acto, Constanze Webber acude a Salieri en un intento por mejorar la situación económica que atraviesa su matrimonio. Le pide que consiga un 
puesto de trabajo para su esposo dentro de la corte. Salieri solicita ver manuscritos de su rival para así evaluar la situación. Las acotaciones en las versiones teatrales ( 1 , 2 y 4) nos indican que Salieri mira con codicia ("greedily") los manuscritos donde se cifra el genio:

She had said that these were his original scores. First and only drafts of the music. Yet they looked like fair copies. They showed no corrections of any king. It was puzzlingthen suddenly alarming. [...] What was evident was that Mozart was simply transcribing music completely finished in his head. And finished as most music is never finished. [...] I was staring through the cage of those meticulous ink strokes at -an Absolute Beauty! (Shaffer, 2001: 57). ${ }^{2}$

La perplejidad de Salieri no solo muestra admiración: muestra temor. Esa mezcla de emociones conflictivas podría relacionarse con la estética de lo sublime, ese concepto de Kant y Burke que habla de la experiencia perceptiva frente a lo que rebasa nuestra capacidad de asimilación y comprensión (Gagliardi, 2016: 76). Mozart no solo es sorprendente: es monstruoso por su prodigiosa habilidad compositiva. Su escritura impoluta muestra lo que, en la paranoia de Salieri, es prueba irrefutable. Si nos retrotraemos a los primeros pasajes de Amadeus en todas sus encarnaciones recordaremos que Salieri pidió ser un compositor famoso y capaz de escribir música que alabase la gloria de Dios, pero aquí advierte que Dios ha elegido a Mozart para hablar a través de sus pentagramas. Salieri quiere gritar «Esos condenados manuscritos» en referencia a los papeles que a la vez muestran la genialidad y son prueba de la existencia de una esfera a la que Salieri tiene vedado el acceso.

La reacción del personaje en las versiones teatrales es elocuente: deja caer los manuscritos y se desploma "senseless" luego de experimentar el talento que ha percibido en las escrituras de su rival. Acto seguido, Salieri inicia un monólogo en el cual increpa a Dios y jura ser su enemigo (2001: 59). Este parlamento es proferido en todas las versiones sobre la alfombra de manuscritos que ha quedado sobre el escenario. Como veremos, la misma presagia la alfombra o lecho manuscritos sobre la cual Mozart queda hacia el final de la obra. La versión 3 (guión cinematográfico) también muestra a Salieri dejando caer las partituras, pero su invectiva no es pronunciada allí, sino en otra escena. Salieri extorsiona a Constanze para que se entregue sexualmente a él a cambio de conseguir el puesto para Mozart (Shaffer, 1982: Esc. 74). Mientras Constanze se desviste, los manuscritos caen nuevamente en paralelo a la progresiva desnudez de la muchacha. La acotación del guión indica:

She looks at him inquiringly, and drops the portfolio on the floor; pages of music pour out of it. Instantly we hear a massive chord, and the great Tui Tollis from the Mass in $C$ Minor fills the room. To its grand and weighty sound, Constanze starts to undress, watched by the horrified Salieri. Between him and her, music is an active presence, hurting and baffling him.

La desnudez de Constanze y la desnudez figurada de Mozart ante los ojos de Salieri lo horrorizan. Luego de echar a la esposa de su rival, Salieri pronuncia su invectiva frente a una chimenea donde quema un crucifijo.

Lo que observamos en estos fragmentos de las cuatro versiones es la persistencia de la representación del manuscrito como monumento que atestigua el proceso histórico de escritura y al genialidad consignada allí, uno de los roles asignados frecuentemente a estas escrituras según ha postulado la crítica genética (Lois, 2001; 2005).

Dado que este fragmento se repite sin modificaciones en todas las variantes escriturales de la obra referidas, citamos a partir de la edición más reciente. 


\section{Escritura peligrosa y espacialidad}

A partir de lo expuesto en el apartado anterior podemos trazar una asociación entre la escritura concebida como un peligro y la espacialidad.

Cuando Salieri refiere al público las sensaciones que experimentó al inspeccionar las partituras, él manifiesta que ve la música volcada en la partitura como si estuviera observando a través de una jaula o celda cuyos barrotes serían los trazos de tinta («ink strokes») y el pentagrama. Salieri convierte una simple hoja y sus trazos en un territorio dividido entre el adentro y el afuera. Esta división tajante es la que el personaje compensa con una transgresión constante de la cuarta pared. Si Salieri está imposibilitado de acceder al interior de las partituras, él diseña una situación enunciativa en la cual pueda generar su propio adentro/afuera por medio de la relación que le hace al público. El personaje, de hecho, invoca al público bajo el apelativo de "Ghosts of the Future" al inicio de la obra e intenta establecer complicidad por medio de la ironía (Gagliardi, 2015; 2016: 51)

Esta dimensión espacial-territorial forma un circuito con otras observaciones afines que el texto dramático propicia. Poco después de el episodio al que me he referido, el propio Salieri afirma "My quarrell now wasn't with Mozart-it was through him! Through him to God, who loved him so" (2001: 62). La preposición especial "through" ubica a Mozart en el rol del territorio de la disputa; recordemos que el texto presenta también algunas metáforas de corte bélico que organizan el conflicto para el resto del drama: Mozart es para Salieri el campo de batalla ("battleground") y el territorio mediante el cual bloquear ("block") la voz de Dios (Shaffer, 1980: 83; 1984: 78; 2001: 61). Salieri toma el veneno de la escritura de Mozart y lo transforma en un nuevo veneno: un curso de acción bélico en expresa su logística siniestra. Al protagonista solo le resta comenzar a poner barricadas y preparar sus mejores armas. Mozart debe ser invadido entonces.

Una comparación del texto dramático con la reelaboración que supone el guión para la película de Milos Forman puede resultar esclarecedora para ver cómo la espacialidad y la escritura aparecen asociadas en todas las reescrituras de Amadeus a modo de constante.

En la versión 3, uno de los cambios más evidentes con respecto a los textos dramáticos es que Salieri contrata a una espía, Lorl, para que haga las veces de empleada doméstica de Mozart; esta tarea es llevada a cabo parcialmente por los venticelli de Salieri en las variantes para el escenario. Una tarde, mientras la familia no se encuentra en la casa, Salieri se presenta al domicilio de su rival. El guión nos indica lo siguiente: "Salieri enters the private quarters of Amadeus". La metáfora dentro de esa acotación sería innecesaria desde un punto de vista de la trasposición cinematográfica, pues esa no quedaría verbalizada dentro del filme; la connotación bélica de esa expresión no necesariamente pasaría al lenguaje visual tampoco, sino que se constituye como un resto. ${ }^{3}$ Si esta indicación parece superflua dentro de las acotaciones de un guión cinematográfico, resulta interesante como gesto escritural: se muestra como gesto insistente de las territorializaciones dentro del texto y del armado de un sistema de metáforas de guerra, aun cuando probablemente vaya a perderse en la trasposición. Por otro lado, este fragmento del guión asocia la penetración en el espacio privado -acaso eco del fallido intento de poseer sexualmente a Constanze en cualquiera de las variantes- se asocia a la escritura nuevamente. Salieri explora los elementos de la casa, los toca, los deja hasta llegar a los manuscritos dispersos sobre el escritorio y la pluma que acaricia como si perteneciera a un ser amado ("memento of a beloved", indica el guión dentro de la misma escena). El motivo espacial que el guión había trasladado a la acotación ahora vuelve sobre los manuscritos como espacio
3. Mariano Zucchi (2016) realiza un interesante análisis de las didascalias de Miniana y concluye que las mismas no siempre brindan instrucciones para la puesta en escena, sino información que no es inmediatamente trasladable a la creación del hecho teatral. Fragmentos como el que hemos citado a partir del guión (y otros presentes en los textos dramáticos de Shaffer) nos permiten suponer que ese resto de significación no traducible constituye una unidad escritural donde podemos analizar persistencias que, a modo de pulsión en la escritura, emergen más allá de poseer una utilidad y dan cuenta entonces de un imaginario en el caso shafferiano. 
creativo en el que se territorializa una disputa. La escritura de las partituras en cuestión pertenece a Las bodas de Fígaro, con la cual Salieri tratará de intrigar en contra de Mozart convenciendo al Emperador del inapropiado contenido de esta nueva obra.

\section{Escritura venenosa y sexualidad}

Volvamos al contacto inicial de Salieri con los manuscritos que las didascalias indican cómo Salieri (y el espectador) escuchan fragmentos de la música volcada en las partituras que Constanze le había facilitado. La reacción de Salieri llega a un éxtasis en el cual nuevamente advertimos la amalgama de placer, miedo y dolor de lo sublime.

Acto seguido, Salieri chantajea sexualmente a Constanze en todas las versiones. En este punto vemos una segunda asociación: escritura y sexualidad. Salieri intercambia sus favores a cambio de sexo y de la posibilidad de revisar los escritos. Pero el horror de las partituras hace que abandone su plan de seducción de Constanze. Seducirla es invadir el territorio que para el italiano pertenece a Mozart; tener sus manuscritos es entrar en contacto con la mente del genio. Ambas experiencias, puestas en correlación dentro de la misma escena, solo culminan en más horror. El Salieri de las versiones teatrales inicia un camino en el cual seducirá luego a Katherina Cavallieri, alumna suya y amante de Mozart. El Salieri del cine seguirá siendo rígidamente casto hasta el final del metraje. Observaremos también la correlación escritura-veneno-sexo en la escena de escritura del Réquiem, más adelante.

La escritura del Requiem es una secuencia que Shaffer concibió exclusivamente para el guión como forma de confrontación final entre sus dos protagonistas. ${ }^{4}$ Un análisis de la misma nos permite ver el modo en que la versión cinematográfica enfatiza el elemento sexual en relación con la escritura a diferencia de los textos dramáticos.

4. En Gagliardi (2016) se realiza un análisis más detallado de las diferencias que implica este cambio en el desenlace de Amadeus.

Salieri convence a Mozart de terminar la partitura de la que será su última obra. En este extenso pasaje de notaciones musicales con sus marchas y contramarchas, Salieri logra ponerse en contacto por escasos segundos con la prodigiosa máquina compositiva y su lógica. En esta escena marcada por la intimidad de la habitación, la falta de pelucas y parte de sus atuendos se despliega la escritura como una suerte de sublimación y medio por el cual Salieri entra en contacto con Mozart, un contacto que incluso puede adquirir connotaciones sexuales. Baste recordar que finalizada esta escena, Constanze regresa a la casa y encuentra a su marido y a Salieri dormidos en la habitación. Las indicaciones de Shaffer sitúan a Mozart en su cama y a Salieri durmiendo en posición fetal en un banco del otro extremo del cuarto (Shaffer, 1982: Esc. 168C). Si nos remitimos al largometraje de Milos Forman vemos como el plano subjetivo que representa la mirada de Constanze al entrar a la habitación traza una línea desde Mozart en su lecho hasta Salieri en el otro extremo, es decir, que los une a ambos en una continuidad dentro de un espacio asignado a la intimidad de la pareja. La reacción de Constanze es pedirle a Salieri que se vaya, quizá no sólo por el chantaje que experimentó con anterioridad, sino también por la connotación sexual de la escena.

Mozart lies asleep in the bed, holding the last pages of the manuscript. Salieri lies across from him on Karl's small bed in his shirt sleeves and waistcoat. The child's bed is obviously too small for him and he is forced in to a cramped position (Shaffer, 1982: Esc. 168C).

Mozart is asleep in the bed. Salieri is dozing on the nearby child's bed. The room is full of the trailing smoke from guttering and guttered candles. Startled by Constanze's entrance and her young son, Salieri scrambles up. As he does so, he attempts to button his waistcoat, but does it ineptly, so that the vestment becomes bunched up, making him look absurd (Shaffer, 1982: Esc. 171). 


\section{Escritura y oralidad: perdurabilidad y leyenda}

Otro posible punto de entrada a la constelación escritural de Amadeus puede ser la revisión de las oposiciones entre oralidad y escritura y el modo en que la misma organiza el conflicto entre los protagonistas. Entre las oposiciones más difundidas suelen mencionarse la permanencia del registro grafemático frente a la evanescencia de la palabra dicha (Verba volant, scripta manent). No por ser un lugar común deja de ser una idea relevante: dentro de Amadeus podemos observar distinciones entre oralidad y escritura que van ligadas a la idea de perdurabilidad en la línea de las reflexiones platónicas y derrideanas. La incisión que traza lo escrito es una incisión en el material, pero también en el tiempo. En este sentido, podemos observar las diferencias entre Mozart y Salieri.

Lo primero a destacar es cuáles son instancias de escritura que se muestran en Amadeus. En las versiones teatrales no se registran momentos en que los personajes tomen la pluma y papel: se leen cartas con malas noticias y periódicos, se ven los manuscritos perfectos de Mozart, pero no se muestra a nadie mientras escribe. No obstante, en forma tácita resuena constantemente la escritura del Réquiem, la cual se vuelve una carrera contrarreloj debido a la presencia acosadora del mensajero que persigue a Mozart. ${ }^{5}$

En esta situación se presenta una evidente asociación entre escritura y muerte. El creciente malestar psíquico y físico de Mozart lo lleva a identificar la música que le es encargada por el falso mensajero con la música de su propio funeral:

Mozart: Isn't it obvious? [Pause] It's for me, that's all.

\section{Salieri: What?}

Mozart: [Factually]. The Mass. It's for me. Myself... It's ordered. I am to write my own! Isn't it obvious? [Pause] It's for me, that's all (Shaffer, 2001: 105).

Salieri también llega a esa identificación en la versión 3: de acuerdo con sus planes, hará pasar la pieza musical como una composición suya para el funeral de Mozart (1982: Esc. 142). El plagio es, a estas alturas, el único modo en que Salieri vislumbra la posibilidad de acercarse al genio de su contrincante y de realizar la mayor afrenta posible al Dios que utiliza a Mozart como títere. Por otro lado, el plagio en tanto avance sobre el otro podría pensarse en paralelo al mencionado intento de Salieri por seducir a Constanze. Si el plagio es una perversión del original, es un efecto de la separación de la escritura de la mano de su creador, es decir, una reedición de la inquietud platónica por el sentido y, por extensión, de la autoría intelectual.

En el guión cinematográfico, a diferencia de las otras variantes escriturales, sí se muestra procesos de escritura. Por ejemplo, durante una riña doméstica entre Constance y Leopold, Mozart se encierra en una habitación para seguir escribiendo (1982: Esc. 97-98). Las indicaciones lo muestran escribiendo sobre una mesa de billar, tarea que interrumpe a intervalos regulares para jugar con una de las bolas; tenemos aquí un matiz lúdico que se agrega al continuum de representaciones de lo escrito en Amadeus. No obstante, el guión y el largometraje, aunque confieran algunos nuevos matices, también refuerzan la imagen siniestra de lo escrito.

En paralelo con el Réquiem, Mozart compone La bodas de Fígaro. Constanze lo interpela diciéndole que la música fúnebre será mejor pagada y que debe abocarse a finalizarla en lugar de seguir con la ópera cómica. Mozart se niega: "It's killing me" (Esc. 147) dice en relación con la escritura para el Mensajero. Como para reforzar aún más el cariz siniestro de esa masa escritural, luego de la discusión, Mozart continúa dando forma a su partitura. El guión indica:
5. En uno de los planes de Salieri, él se disfraza de un mensajero encapuchado que encarga el Requiem y acosa a Mozart para que lo termine. Esto tiene sus bases en hechos históricos: Franz von Walsegg (1763-1827), un aristócrata austríaco, fue quien encargó la misa de réquiem por medio de un emisario misterioso. Músico amateur, quería el réquiem para el funeral de su esposa, pero deseaba hacerlo circular como producto de su autoría. Shaffer retoma esta historia y la convierte en parte de su ficción. 
We hear the Rex Tremendai Majestatis from the Requiem and see on the wall the portrait of Leopold Mozart looking down. The camera pans slowly downward from it back to the table. Mozart is writing the music. (1984: Esc. 147)

Asistimos nuevamente a la aparición de la figura paterna como lo inquietante, algo que la película hace explícito dado que Leopold Mozart es un personaje secundario, a diferencia de las versiones escénicas donde sólo es mencionado o se ve su retrato (Gagliardi, 2016). Posteriormente, el poder venenoso de la escritura será advertido por Constanze. Al regresar a casa y tratar de recomponer su relación con Mozart, ella le prohíbe terminar el Réquiem, porque reconoce que lo está enfermando (Esc. 171).

A través de estas escenas se pone de manifiesto la escritura como archivación, como incisión temporal y perdurabilidad: las partituras, peligrosas de uno $\mathrm{u}$ otro modo para ambos protagonistas, se oponen a la evanescencia. Salieri sabe que el Réquiem y el resto del repertorio mozartiano va a perdurar. La escritura de Mozart se muestra en escena y en pantalla. Salieri nunca es mostrado componiendo y su única partitura es despedazada: la marcha que compone para dar bienvenida a Mozart a la corte será reutilizada y modificada por el austríaco para Las bodas de Fígaro en una situación de plagio. Frente a la monstruosidad perfecta de Mozart, los pentagramas de Salieri son deglutidos. Sin embargo, el hecho de que Mozart plagie la marcha de Salieri en cualquiera de las versiones supone un detalle mediante el cual Shaffer ingresa una visión iconoclasta de la leyenda romántica en torno al músico, una que se suma a la risa, la cropolalia y los devenires infantiles del compositor que han sido analizados en otros trabajos (Demeer, 1997; Kurowsa, 1998; Gagliardi, 2014; 2015; 2016).

A Salieri le queda entonces la esfera de la oralidad. Si la escritura es el imperio de Mozart, Salieri ejercitará una práctica tan antigua como delicada en su perdurabilidad: la confesión y el chisme. La obra, como hemos dicho, plantea esta situación enunciativa. Como Salieri sabe que no perdurará su fama solo a partir de lo que ha compuesto, decide auto-difamarse para quedar adosado al nombre de Mozart. En este sentido, el rumor que circula de boca en boca acerca de su responsabilidad en la muerte del rival es otra estrategia de la oralidad asociada al personaje. No sólo son contantes sus conversaciones y chismes con los venticelli: la obra teatral inicia con una superposición de voces que esparcen rumores sobre la culpabilidad o inocencia del italiano. En la versión 3, en cambio, se presenta al compositor gritando a través de su ventana hacia Viena (1982: Esc. 15). Algunos transeúntes lo ven y oyen, pero no se confirma si realmente le creen; el desenlace del guión deja en suspenso si la estratagema ha tenido éxito. El relato de Salieri se pierde en los mares del tiempo, ahogado por la leyenda. Las maledicencias y el chisme, otro género discursivo oral, son usadas como estrategia por Salieri para complotar contra Mozart. Sólo en este terreno de la disputa por la imagen pública a través del rumor Salieri se muestra victorioso frente a su rival: el murmullo del chisme es la única parcela del ámbito sonoro donde parece triunfar en verdad, ya que la música de Mozart también en el resto.

De forma un tanto paradójica, Amadeus logra lo que el ficticio Salieri no pudo hacer: ligar en el imaginario su nombre al de su rival, instituirse como una figura parasitaria y presente. Esta visión del personaje es la que aparece en la canción de León Gieco titulada «Los Salieris de Charly».

Lo que Salieri experimenta desde la oralidad es algo que Fedro asociaba con la escritura: la pérdida del control interpretativo sobre lo transmitido mediante los grafemas. Para Platón, la palabra en la conversación cara a cara puede ser reformulada, explicada, ampliada de modo al que el usuario de la lengua tenga cierto grado de control o autoridad sobre lo dicho. No obstante, podemos pensar que Platón no tuvo en cuenta el rol de la transmisión oral de boca en boca, pues el rumor y su mecánica 
son similares a la posible des-sujeción del escritor para con su escritura. El rumor trasciende las intenciones y previsiones originales. La transmisión oral desborda cualquier autorictas.

\section{Escrituras y discusiones: revisitando la intertextualidad}

Para cerrar estas reflexiones, exploraremos las relaciones polémicas que se pueden establecer dentro la escritura de Amadeus. Retomamos la intertextualidad que existe entre las obras de Alexandr Puskin y Peter Shaffer.

La crítica ha recurrido con frecuencia a comparaciones entre Amadeus y la pieza en un acto Mozarty Salieri (1830), ${ }^{6}$ de Alexander Pushkin, que fuera adaptada posteriormente por Nikolas Rimsky-Korsakov (1898) en forma de ópera. En entrevistas que Peter Shaffer brindó durante las primeras producciones de la obra y en declaraciones posteriores, afirmó desconocer el texto de Pushkin (Borowitz, 2005: 140). Si seguimos estas declaraciones, la pieza del escritor ruso no sería un enunciado que Shaffer hubiese tenido en consideración ya sea para escribir en consonancia o en contra del mismo. No obstante, la exogénesis (Lois, 2001:20; 2005: 91) del proceso escritural nos permite pensar que aunque la pieza de Pushkin no fuera un intertexto consciente para la primera versión de escrita por Shaffer, sí lo sería para las reescrituras. ${ }^{7}$

La pieza de Pushkin se concentra sólo en los dos personajes y la despoja de las dimensiones metafísicas y teológicas que el Salieri shafferiano inyecta al conflicto. Salieri es en este caso un compositor metódico, asociado a una forma de trabajo creativo cuasi matemática y Mozart, nuevamente, el compositor vivaz y genial del Romanticismo. El desenlace de la obra muestra a Salieri envenenado literalmente a su rival, algo que la versión de Shaffer se niega persistentemente a hacer. Shaffer ha establecido que una de sus inquietudes era resolver la muerte de Mozart sin que Salieri fuera el ejecutor de la misma, una persistencia en todas las versiones (2001: xxvi). Esta preocupación aparece manifiesta en el discurso del personaje en la versión 3, de hecho:

\section{OLD SALIERI:}

The only thing that worried me was the actual killing. How does one do that? How does one kill a man? It's one thing to dream about it. It's very different when you have to do it, with your own hands (Shaffer, 1982: Esc. 142).

El gesto de evitar convertir al protagonista en asesino genera una polémica con el abordaje que Pushkin realizara sobre estos personajes; se genera una tensión en torno a la idea del envenenamiento. Mientras que en Mozarty Salieri, el italiano desliza veneno en la copa de su rival, el Salieri de Shaffer envenena lentamente mediante la escritura cargada de connotaciones perniciosas. En la versión tercera, entonces, forzar a su enemigo a escribir la música de la muerte es administrar dosis de ponzoña al sistema circulatorio de su rival con la ignorante complacencia de aquel. Un examen a los matices que adquiere la escritura en el caso de Pushkin basta para ilustrar la diferencia de imaginarios que ambos dramaturgos construyen: cuando su Mozart refiere al encargo del Réquiem dice que se sentiría mal de separarse del mismo y que ya lo ha terminado (1830: 77); por el contrario, el Mozart shafferiano no culmina su obra y tampoco desea hacerlo más que para cumplir el trato y bajo amenaza.

El final del segundo acto de Amadeus retoma la idea del envenenamiento en al menos dos formas. En la versión 4 -a diferencia de las 1 y 2-Salieri no ingresa a la casa de su rival bajo el disfraz del mensajero siniestro: la máscara no lo cubre, aunque Mozart inicialmente no lo reconozca por la oscuridad de la noche. En un interesante
6. Aunque fuera terminada en esta fecha, existen datos de que Pushkin comenzó a escribirla en 1926, es decir, un año después de la muerte de Antonio Salieri, cuando los rumores sobre su responsabilidad en la muerte de Mozart aún se encontraban circulando (Borowitz, 2005: 140).

7. Este problema filológico es abordado en Gagliardi (2016: 57). 
detalle escénico agregado por esta versión los huecos en las ventanas de la casa de Mozart están rellenados con trozos de papel y pergamino de sus partituras (Shaffer, 2001: 106). Durante esta secuencia, el propio Salieri termina por confesar su complot luego de quedar apabullado por la música que emerge de los manuscritos del Réquiem dispersos por la sala, una escena que reedita el episodio sufrido anteriormente ante Constanze. En esta variante, el italiano desdice a Mozart: la música del requiem es en realidad para aquel niño que Salieri fue alguna vez, ese que deseaba ser un compositor y al cual él mismo dice haber asesinado a lo largo de diez años de intrigas (Shaffer, 2001: 107). El compositor se muestra arrepentido y pide unas disculpas que no llegan a sustanciarse. Se suscita una escena que conviene detallar: Salieri le dice a Mozart que ambos están envenenados. En un acto desesperado para que el austríaco comprenda la situación, Salieri come fragmentos de la partitura mientras dice "I eat what God Gives me. Dose after dose. For all of life!" (2001: 108) en una especie de parodia de la eucaristía cristiana.

La elaboración que la versión 2 hace de esta secuencia es un tanto diferente en cuanto a los presupuestos e intenciones de Salieri. Mientras que como Shaffer expresa (2001: viii), la cuarta variante busca enfatizar el arrepentimiento del italiano, las versiones anteriores lo mostraban resuelto a llevar a cabo su venganza hasta las últimas consecuencias. En este sentido, el Salieri de esta variante escénica, aún disfrazado como el mensajero desgarra uno de los manuscritos y lo come simulando una ceremonia eucarística. De inmediato dice: «[In pain] I eat what God Gives me. Dose after dose. For all of life. His poison. We are both poisoned, Amadeus. I with you: you with me" (1984: 139). Luego, Mozart le quita la máscara y descubre la identidad del mensajero. ${ }^{8}$ Lejos de ser una señal de arrepentimiento (querer equipararse a la situación de su víctima) este Salieri sólo admite estar en la misma situación para aterrar a su rival.

Una misma acción. Frases extremadamente similares en sus selecciones léxicas. Sin embargo, algo ha cambiado: la entonación de este acto y esas frases. Los cambios operados en el resto del texto generan ecos que repercuten sobre esta secuencia resinificándola por completo: de un lado, tenemos un gesto más para atemorizar a Mozart; del otro, un intento de equipararse al agonizante músico austríaco. A pesar de que en v.2, como en v.3, Salieri no muestra arrepentimiento alguno, este gesto lo une momentáneamente a su enemigo: reconoce que ambos están envenenados, que constituyen dos criaturas a las que la divinidad les ha soltado la mano.

Luego de este duelo, en las versiones teatrales, Constanze reaparece en el hogar y encuentra a su esposo sobre un montón de manuscritos que oficia de lecho mortuorio y contrapunto del que Salieri usara para lanzar su juramento de venganza contra Dios. Este le dice que Salieri lo ha matado. Constanze no da crédito de sus palabras, porque considera que su esposo delira por la fiebre. Momentos después, Wolfgang muere en brazos de ella.

Como dijimos anteriormente, Pushkin escenificó un envenenamiento en su sentido más literal; a su vez hace que Salieri le haga tocar a Mozart el réquiem hasta morir. Mozart fallece inmerso en su obra, aunque de un modo sutilmente distinto al lecho escritural en que Shaffer le quita sus últimos alientos al personaje. El dramaturgo inglés hace que Mozart quede apresado por su máximo temor, el de haber escrito su propia muerte. Aquí hay una zona donde Pushkin y Shaffer coinciden aún por medio de herramientas escénicas disímiles. No obstante, la polémica entre ambos autores queda establecida en tanto la falta de autoría material directa del Salieri de Shaffer en la muerte de Mozart aviva el fuego del conflicto espiritual de su personaje: ya sea en el Salieri enardecido o en el caso el arrepentido, él se ve a sí mismo como víctima, una vez más, de las jugarretas de Dios en su contra.
8. Parte de esta situación surgió a partir de los ensayos para el montaje realizado en Broadway en 1980. El actor lan McKellen (quien interpretó a Salieri) fue clave en la delimitación de esta escena dado que sugirió algunas de estas acciones que luego Shaffer incorporó a la escritura en la versión 2. 


\section{A modo de conclusión}

El análisis de este imaginario en torno a la escritura, su autoría, circulación, soporte y valores permite esbozar las siguientes conclusiones: 1 ) desde el punto de vista de los estudios geneticistas confirma que podemos localizar persistencias y conflictos discursivos no advertidos en el proceso escritural que sobreviven incluso a cambios de género discursivo (texto dramático a guión, en este caso), los cuales dan cuenta de ciertos hilos interpretativos a reconstruir; 2) en el marco de los estudios teatrales, el examen de un motivo, un imaginario en la obra de un autor (incluso en aquellas escrituras por fuera de las destinadas específicamente a la escena) permite advertir recurrencias que pueden resultar relevantes para la investigación teatral y la toma de decisiones acerca de la puesta en escena.

Como hemos observado a lo largo de este artículo, Shaffer desarrolla un imaginario en torno a lo escrito. Recupera cierto fetichismo del manuscrito como lugar de operación del genio visionario, genio que fascina al punto de generar horror. Lejos de ser el territorio donde se deposita la explicación, la verdad sobre el arte y el genio creador, el manuscrito de Mozart es para Shaffer el terreno de la monstruosidad y de la envidia por esa condición de monstruo que es inalcanzable para el resto. La envidia lo lleva a diseñar un curso de acción que funciona como una suerte de manual de instrucciones para envenenar a un compositor. Uno de los pasos, si no el más importante, es hacerlo escribir una oscura misa de réquiem. 


\section{Bibliografía}

》Calvet, J. P. (2007). Historia de la escritura: de Mesopotamia hasta nuestros días. Barcelona: Paidós.

" Cismondi, C. (2011). "Variaciones teatrales de crítica genetic". Manuscrítica, 10 (11), $15-60$.

»Deemer, C. (1997). “Fine-Tuning Villainy. Salieri's Journey from Stage to Screen". Creative Screenwriting [en línea]. Consultado el 9 de febrero de 2018 en $<$ https://goo.gl/SsrmTx>.

"Derrida, J. (1971). Márgenes de la filosofía. Madrid: Cátedra.

»Dubatti, J. (2008). "Escritura teatral y escena: el nuevo concepto de texto dramático". Revista Colombiana de las Artes Escénicas, 2 (2), 7-18.

» Gagliardi, L. (2015). “'Un saludo a los fantasmas del futuro o cómo leer la temporalidad en Amadeus de Peter Shaffer". Ponencia presentada en el II Congreso de la Delegación Argentina de la Asociación de Lingüística y Filología de América Latina (ALFAL) y VII Jornadas Internacionales de Investigación en Filología y lingüística, realizado en La Plata, 21 al 24 de abril de 2015.

" Gagliardi, L. (2014). “La genética textual como lectura comparatista. El caso de la génesis de Amadeus, de Peter Shaffer". Ponencia presentada en las VI Jornadas Internas del Centro de Estudio de Literaturas y Literaturas Comparadas, realizadas en La Plata: 31 de octubre y 1 de noviembre de 2014.

"Gagliardi, L. (2016). Risa, noche y escritura. Génesis escritural de Amadeus, de Peter Shaffer (Tesis). La Plata: Universidad Nacional de La Plata.

» Goldchluk, G. (2010). "El archivo por venir, o el archivo como política de lectura". En: Actas del VII Congreso Internacional Orbis Tertius de Teoría y Crítica Literaria. La Plata: Facultad de Humanidades y Ciencias de la Educación.

"Grésillon, A. (1995). "En los límites de la génesis: de la escritura del texto de teatro a la puesta en escena". Inter Literas (4), 5-14.

» Grésillon, A. (1996). “¿Qué es la crítica genética?”. Filología, XXVII (1/2), 23-36.

» Hay, L. (1996). “La escritura viva”, Filología, XXVII (1/2), 5-22.

»Lois, É. (2005). “De la filología a la genética textual: historia de los conceptos y de las prácticas"; "Las distintas orientaciones hermenéuticas de la investigación geneticista". En Colla, Fernando (coord.), Archivos: Cómo editar la literatura latinoamericana del siglo XX (pp. 47-83). Poitiers: Centre de Recherches LatinoAméricaines; Archivos.

»Lois, É. (2001). Génesis de escritura y estudios culturales. Buenos Aires: Edicial.

"Shaffer, P. (1980). Amadeus. Londres: André Deutsch.

"Shaffer, P. (1982). Amadeus: the screenplay. Ms.

》Shaffer, P. (1984). Amadeus. Londres: Harper Perennial.

"Shaffer, P. (2001). Amadeus. Londres: Harper Perennial.

»Zucchi, M. (2016). “Didascalias y subjetividad. Análisis de la figura del locutor en el texto segundo de Inventarios de P. Minyana". Ponencia presentada en IV Congreso Internacional Artes en Cruce Constelaciones de sentido. Universidad de Buenos Aires. 